\title{
Cider Proteins and Foam Characteristics: A Contribution to Their Characterization
}

\author{
Domingo Blanco-Gomis, ${ }^{*}, \dagger$ Juan J. Mangas-Alonso, ${ }^{\S}$ \\ SARA Junco-Corujedo,$^{\dagger}$ AND M. Dolores GutiérRez-ÁlvareZ ${ }^{\dagger}$ \\ Departamento de Química Física y Analítica, Facultad de Química, Universidad de Oviedo, \\ Julián Clavería 8, E-33006 Oviedo, Asturias, Spain, and Servicio Regional de \\ Investigación y Desarrollo Agroalimentario (SERIDA), Carretera Oviedo s/n, Apartado 13, \\ E-33300 Villaviciosa, Asturias, Spain
}

\begin{abstract}
A capillary sieving electrophoretic method for protein analysis and molecular weight determination was used to characterize ciders from Asturias, northern Spain. The total protein content (Bradford method) and the foam parameters (Bikerman method) were also analyzed to complete this characterization. The polypeptide profile, based on the molecular weight, together with exploratory and classification techniques, that is, principal component analysis (PCA) or linear discriminant analysis (LDA), allowed ciders to be differentiated on the basis of their foam assessment and the apple juice extraction technology used in the cidermaking process. In addition, the application of correlation analysis, that is, canonical correlations (CCA) or partial least-squares (PLS), revealed that the proteins with higher molecular weight were more relevant with respect to cider foamability. PLS analysis also provided a mathematical equation that is able to predict the stabilization time of foam from the polypeptide profile of the cider, because this is the foam parameter most influenced by these compounds.
\end{abstract}

KEYWORDS: Cider; proteins; capillary electrophoresis; foam properties; chemometrics

\section{INTRODUCTION}

Cider is one of the most important agrofood products in the Principality of Asturias. Annual production is around 820000 $\mathrm{hL}$ according to the Regulatory Council for the Protected Designation of Origin "Sidra de Asturias" (data of the 2004 vintage). Fifty-five percent of this production corresponds to "natural" still cider, a popular beverage especially linked with the history of Asturias.

Improving and maintaining the quality of Asturian ciders is of vital importance for the consolidation and expansion of the cider market for Designation of Origin beverages. Cider quality involves visual attributes, taste, and odor perceptions. Among the visual attributes, foam characteristics are determinant in the quality assessment of this beverage, highly significant correlations being detected between foam and odor and taste qualities. In "natural cider", good foaming behavior includes major foam formation when it is poured into the glass (which is traditionally done from a height in Asturias), rapid disappearance of this foam, which passes into the cider forming little bubbles of $\mathrm{CO}_{2}$, and, finally, a residue of thin foam remaining in the glass.

Several studies have concluded that polysaccharides, fatty acids, and proteins are important molecules in foam constitution

* Author to whom correspondence should be addressed (telephone +34 985-103490; fax +34-985-103125; e-mail dbg@fq.uniovi.es).

$\dagger$ Universidad de Oviedo.

$\S$ SERIDA. and stabilization. For instance, Mangas et al. (1) described the effect of methanol (a molecule linked to pectic substances in the apple) and acidic polysaccharides on the foam stability of cider, and Margolles et al. (2) established significant mathematical correlations between foam characteristics and the fatty acid composition of cider. Likewise, Siebert and Knudson (3), Kano and Kaminura (4), Hsu et al. (5), and Polo et al. (6) demonstrated the importance of the protein profile (based on molecular mass) on the foam composition, stabilization, and characterization of beer, wine, and grape must.

Proteins are known to contribute to the formation and stabilization of foams. Three stages are involved in these processes: (i) diffusion of the protein to the gas/liquid interface; (ii) unfolding of the protein at the interface; and (iii) interaction among protein molecules to form a stabilized film around the bubbles (7). This important role of proteins may be explained by their ability to decrease interfacial tension and to increase the viscous and elastic properties of the film as a result of the formation of hydrogen bonds and electrostatic and hydrophobic interactions. The characteristics of proteins that affect foaming ability are their molecular flexibility (related to the number of SS linkages/molecular weight), their amphipathic properties (the unfolding facility is improved by the number of hydrophobic groups), their hydrophobic properties (8), and their size.

To carry out a study on the foam of a sparkling beverage, it is necessary to measure its foaming properties, the parameters 
traditionally used for this purpose being foam height $(\mathrm{FH})$, foam stability height (FS), and foam stability time (ST). FH is related to foamability, FS represents the ability to maintain a stable collar, and ST is linked to foam stability. Several authors $(9-11)$ have studied the influence of grape varieties, base wines, and aging time on lees in the foaming properties of Cava and Champagne, using these parameters.

This paper describes the study of cider proteins, based on their molecular masses, and the cider foam characteristics $(\mathrm{FH}$, FS, and ST). With this purpose in mind, a capillary electrophoretic method developed by our research group $(12,13)$ was employed, separating the SDS-protein complexes in a sieving matrix of linear polyacrylamide. The aim of the study was to determine the molecular masses of the protein profiles and the foam properties of "natural" ciders from Asturias in order to carry out their characterization and to find mathematical relationships between protein and foam characteristics.

\section{MATERIALS AND METHODS}

Ciders. Natural ciders $(n=32)$ were supplied by several cellars from the Principality of Asturias. All of the ciders were made with Asturian cider apple varieties, grown in the central eastern area of Asturias, northern Spain. Juice extraction was carried out using mechanical or hydraulic presses (slow extraction process) or pneumatic presses (fast extraction process).

The database used consisted on 32 rows of "natural" ciders and 33 columns of polypeptides. Ciders were grouped on the basis of two characteristics: the apple juice extraction technique used in their making and the visual aspect assessment of their foam attributes ("foam head", "foam emulsion", and "lacing"). The cidermaking technique led to two groups: the fast extraction process category, which included 15 samples, and the slow extraction process category, which was made up of the rest. Foam assessment, which was carried out by the suppliers of the samples, led to other two categories within the 32 ciders: the good foaming quality group, with 16 samples, and the poor or neutral foaming quality group, with the other 16 samples. The latter group included ciders that form stable foam when they are poured into the glass.

Electrophoretic Analysis. Electrophoretic analyses were carried out on a Hewlett-Packard (Waldbronn, Germany) ${ }^{3 \mathrm{D}} \mathrm{CE}$ apparatus equipped with a diode array detector and a HP ChemStation software package. Fused silica capillary tubes with $100 \mu \mathrm{m}$ internal diameter were purchased from Tecknokroma (Barcelona, Spain). These capillaries were filled with lineal polyacrylamide and a background electrolyte of Tris and aspartic acid.

Reversed polarity at $20 \mathrm{kV}$ and hydrodynamic injection (50 mbar, $50 \mathrm{~s})$ were used in the analysis of the SDS-protein complexes. Detection was performed at $220 \mathrm{~nm}$.

The samples were treated as follows. The cider was sonicated, centrifuged, and filtered before being purified and concentrated (50 times) in the Ultrafree Centrifugal filter device. A solution of SDS and Tris was added to the concentrate, which was then boiled with 2-mercaptoethanol for $10 \mathrm{~min}(12,13)$. The molecular mass standard proteins [aprotinin, $7 \mathrm{kDa}$; lysozyme, $14.5 \mathrm{kDa}$; trypsin inhibitor, 21 $\mathrm{kDa}$; carbonic anhydrase, $31 \mathrm{kDa}$; ovalbumin, $45 \mathrm{kDa}$; bovine serum albumin (BSA), $66.5 \mathrm{kDa}$; and $\beta$-galactosidase, $112 \mathrm{kDa}$ ] were only dissolved in the SDS-Tris solution and boiled as the sample.

Foam Property Measurement. Bikerman's method was adapted to analyze foaming parameters in cider. A glass column of $50 \mathrm{~mL}(60$ $\times 1 \mathrm{~cm}$ ) fitted at the bottom with a sintered glass disk (pore size 10 $\mu \mathrm{m})$ was used. The gas flow (carbon dioxide) was controlled by means of a pressure regulator. Ten milliliters of cider, previously degasified (2 min under vacuum and shaking) at $20^{\circ} \mathrm{C}$, was poured into the column. Carbon dioxide was sparged through the cider at a flow rate of $30 \mathrm{~mL} / \mathrm{min}$. Maximum height (FH parameter) and stable height (FS parameter) were recorded while a continuous flow of carbon dioxide was maintained. The $\mathrm{CO}_{2}$ flow was then interrupted, and the time elapsed (ST parameter) until all bubbles collapsed was measured. The column was washed before each experiment with $10 \mathrm{~mL}$ of ethanol
Table 1. Summary Statistics for Total Protein Content in Cider Samples

\begin{tabular}{lcccc}
\hline & mean $(\mathrm{mg} / \mathrm{mL})$ & $\sigma$ & $\max (\mathrm{mg} / \mathrm{mL})$ & $\min (\mathrm{mg} / \mathrm{mL})$ \\
\hline total & 19.5 & 3.28 & 25.4 & 12.4 \\
${\text { category } 1^{a}}^{a}$ & 20.1 & 3.69 & 25.4 & 12.4 \\
category $^{b}$ & 18.8 & 2.82 & 23.9 & 13.5 \\
\hline
\end{tabular}

${ }^{a}$ Good-quality ciders. ${ }^{b}$ Neutral or poor-quality ciders.

Table 2. Summary Statistics for Foam Parameters in Cider Samples

\begin{tabular}{lcccc}
\hline & mean & $\sigma$ & $\max$ & $\min$ \\
\hline $\mathrm{FH}(\mathrm{mL})$ & 5.7 & 4.0 & 17.9 & 2.7 \\
category 1a $^{\mathrm{c}}$ & 5.9 & 4.8 & 17.9 & 2.8 \\
category 2 & 5.5 & 3.0 & 12.3 & 2.7 \\
$\mathrm{FS}(\mathrm{mL})$ & 3.8 & 1.7 & 7.3 & 2.3 \\
category 1 & 3.6 & 1.6 & 6.7 & 2.3 \\
category 2 & 4.0 & 1.7 & 7.3 & 2.3 \\
ST (seg) & 22.7 & 17.05 & 89.1 & 10.1 \\
category 1 & 22.8 & 21.0 & 89.1 & 10.4 \\
category 2 & 22.6 & 12.7 & 42.7 & 10.1 \\
& & & & \\
\hline
\end{tabular}

${ }^{a}$ Good-quality ciders. ${ }^{b}$ Neutral or poor-quality ciders.

$95 \%$, three times with $10 \mathrm{~mL}$ of Milli-Q water, and finally with 25 $\mathrm{mL}$ of cider sample. The analyses were carried out in triplicate.

Total Protein Analysis. Quantitative determination of the total protein content was carried out by means of the Bradford assay (14). This assay is based on the specific binding of the Coomassie Brilliant Blue-G250 dye to protein molecules. This organic dye binds to tyrosine side chains, giving a dye-protein complex with an absorption maximum at $595 \mathrm{~nm}$.

Cider samples were purified before the analysis in the Ultrafree Centrifugal filter device, and then the concentrate was dissolved with water until the initial volume was obtained. The calibration curve was built using BSA as standard and a detection wavelength of $595 \mathrm{~nm}$.

Statistical Methods. Analysis of variance (ANOVA) was performed to detect significant differences in total protein concentration and foam parameters among categories. Normality and homogeneity of variances tests were previously carried out. If the homogeneity test was not passed by any variable, a Student $t$ test was performed. Multivariate analyses [principal component analysis (PCA), linear discriminant analysis (LDA), canonical correlations analysis (CCA), and partial least-squares regression (PLSR)] were carried out using the PARVUS statistical package (15). Data were autoscaled before multivariate analysis.

\section{RESULTS AND DISCUSSION}

Cider Characterization Based on Total Protein and Foam Parameters. The statistical analysis started with a univariate analysis of the foam parameters and the total protein concentration. We used ANOVA and Student's $t$ test to compare the means of these parameters, the results of which can be seen in Tables 1 and 2. This analysis did not detect significant differences between the ciders belonging to the two foaming quality categories. To ascertain whether a multivariate analysis would allow us to detect any data structure, a PCA was performed. Differentiation of ciders by visual assessment of their foam was not achieved. However, a data structure based on the extraction technology (fast vs slow) was visualized on the first principal component. In Figure 1, we can see two groups of samples: the ciders on the right side of the plane, which were made using the fast technology, show higher values of the foam parameters (mean values: FH, $9.4 \mathrm{~cm}$; FS, $5.6 \mathrm{~cm}$; ST, $39.1 \mathrm{~s}$ ) than the other group (mean values: $\mathrm{FH}, 3.2 \mathrm{~cm}$; FS, $2.6 \mathrm{~cm}$; $\mathrm{ST}, 11.5 \mathrm{~s}$ ), in which most of the ciders were made using the slow process. This fact could be related to the slightly higher 


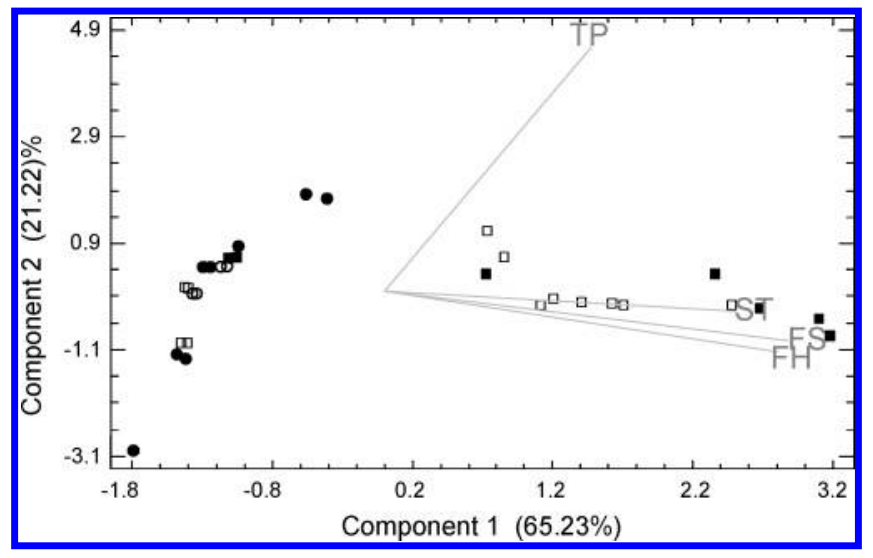

Figure 1. Projection of the samples and variables (TP, FH, FS, and ST) on the plane formed by the first and second principal components: ( $\square$, $\bigcirc)$ good-auality ciders; $(\mathbf{\square}, \mathbf{\bullet})$ neutral or poor-quality ciders; $(O, \mathbf{0})$ ciders made via a slow extraction process; $(\square, \boldsymbol{\square})$ ciders made via a fast extraction process.

Table 3. Molecular Mass and Mean Value of the Areas of Each Individual Polypeptide (POL) Detected in Natural Ciders

\begin{tabular}{lccccc}
\hline POL & $\begin{array}{c}\text { mol mass } \\
(\mathrm{kDa})\end{array}$ & $\begin{array}{c}\text { mean area } \\
(\mathrm{mAU})\end{array}$ & POL & $\begin{array}{c}\text { mol mass } \\
(\mathrm{kDa})\end{array}$ & $\begin{array}{c}\text { mean area } \\
(\mathrm{mAU})\end{array}$ \\
\hline P1 & 8.0 & 0.09 & P18 & 52.0 & 0.22 \\
P2 & 12.1 & 0.08 & P19 & 57.2 & 0.15 \\
P3 & 13.1 & 0.06 & P20 & 60.6 & 0.07 \\
P4 & 14.4 & 0.02 & P21 & 67.3 & 0.19 \\
P5 & 15.7 & 0.02 & P22 & 72.6 & 0.03 \\
P6 & 18.0 & 0.14 & P23 & 75.3 & 0.59 \\
P7 & 20.0 & 0.03 & P24 & 78.6 & 0.18 \\
P8 & 21.0 & 0.05 & P25 & 86.0 & 0.09 \\
P9 & 22.9 & 0.06 & P26 & 93.5 & 0.32 \\
P10 & 24.8 & 0.06 & P27 & 95.5 & 0.61 \\
P11 & 25.8 & 0.11 & P28 & 101.2 & 0.05 \\
P12 & 26.8 & 0.01 & P29 & 111.4 & 0.09 \\
P13 & 28.9 & 0.01 & P30 & 122.0 & 0.15 \\
P14 & 30.6 & 0.05 & P31 & 134.4 & 0.12 \\
P15 & 35.5 & 0.01 & P32 & 14.9 & 0.18 \\
P16 & 39.7 & 0.28 & P33 & 154.4 & 0.22 \\
P17 & 45.0 & 0.10 & & & \\
\hline
\end{tabular}

total protein content of the ciders produced by the fast process for obtaining juice (mean of the right group, $21.0 \mathrm{mg} / \mathrm{L}$; mean of the left group, $17.6 \mathrm{mg} / \mathrm{L}$ ), because the forceful fracture of the fruit generates higher extraction levels of these macromolecules.

Cider Characterization Based on Polypeptide Analyses. Electrophoretic analysis detected 33 polypeptides with a molecular mass ranging from 8 to $154 \mathrm{kDa}$ in the natural cider. The areas of the electrophoretic peaks and their molecular masses can be seen in Table $\mathbf{3}$ and the electrophoretic profile in Figure 2.

$P C A$. We used polypeptides to carry out another screening with the PCA to try to improve the visualization of the data structure obtained with the total protein and foam parameters. Nine factors were computed, with eigenvalues higher than 1.0, accounting for $90.15 \%$ of variance, and two variation sources were detected. Figure 3 shows that the first factor almost differentiates the ciders by the production technology, because most of samples extracted via fast processes are placed on the right side of the plane, with positive values of the first component. Similarly, the second factor almost differentiates ciders by their sensory assessment, most of the good-quality ciders being placed at the top of the plot, with positive values of the second principal component. To complete this analysis,
Table 4 lists the loadings of polypeptides for the two first principal components. Most of the loadings for the second component are positive; thus, they are linked to the ciders of good-quality foaming. Specifically, three polypeptides of "low" molecular mass $(21.0,22.9$, and $25.8 \mathrm{kDa})$ are the ones most associated with these ciders. This result is in agreement with the fact that proteins with good foamability, and probably with bad foam stability, tend to be relatively small (16). At the same time, most of the loadings for the first component are positive, which means that ciders produced by means of fast extraction technology contain higher protein concentrations. Predominantly, there are three polypeptides with high molecular mass $(67.3,75.3$, and $93.5 \mathrm{kDa})$ that are linked to this kind of cider. The more forceful breakage of the parenchyma cells of the fruit produced by means of this technology could promote a higher extraction level of macromolecules of a larger size.

Selection of Variables. As the number of polypeptides used in the PCA was too large, we decided to make a selection of the original variables to avoid colinearities, reduce the noise in the constructed models, and improve the classification of the samples. To choose the most relevant variables, Pearson coefficients were calculated, the Fisher weights of the variables were obtained, and a stepwise LDA was performed. The calculations were made for the two categorical variables foaming behavior and extraction technology, obtaining a better differentiation between the two categories of samples when the variables were reduced.

Classification Analysis. Finally, using the most relevant variables, we computed and validated two decision rules through a LDA to classify ciders by foaming behavior and extraction technology according to their polypeptide profile. Validation was carried out from a cross-validation method using three cancellation groups. For the foaming behavior categorization, the most discriminating variables were found to be P11 and $\mathrm{P} 24$, as they were plotted on an $X Y$ graph obtaining an excellent differentiation of the ciders; the LDA computed with these polypeptides gave $93.6 \%$ classification hits and $87 \%$ prediction hits. If four more polypeptides of high discriminating power (P9, P10, P16, and P18) are added to the data matrix, classification hits reach $100 \%$ and prediction hits $94.1 \%$. Three polypeptides (P21, P8, and P29) were selected at first for the extraction technology, because the resulting $X Y Z$ plot was able to differentiate the two categories. However, the LDA did not reach $100 \%$ in classification hits. Therefore, another four polypeptides (P27, P11, P33, and P2) were included in the classification analysis until $100 \%$ of hits were achieved, obtaining prediction hits higher than $93 \%$. With these results, we can conclude that the mathematical rule is sufficiently reliable and robust for classification purposes.

We can state that electrophoretic analysis of polypeptides based on their molecular size allowed us to characterize "natural" ciders on the basis of visual sensory assessment and extraction technology. Polypeptides with low and medium molecular masses are associated with ciders with good foam assessment, and those polypeptides with the largest size are linked to ciders made via fast extraction technology. Foam quality in cider is dependent on its protein profile. In fact, ciders with a high level of polypeptides of high molecular mass were assessed as good-quality samples in the sensory analysis. Hence, it should be pointed out that other molecules, such as lipids, break up foam and improve foam quality in cider.

Correlation Analysis. Pearson Coefficients. The correlation coefficients between foam parameters and polypeptides were calculated by regression analysis to obtain a preliminary view 


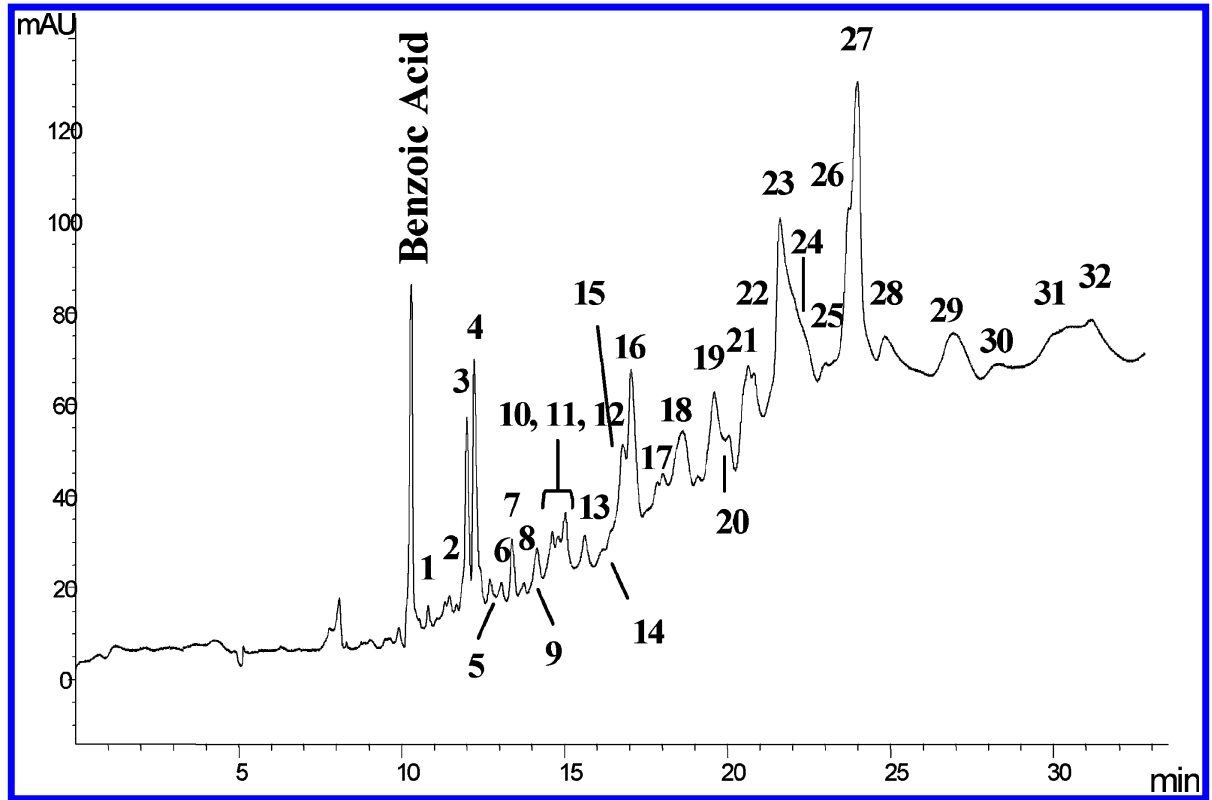

Figure 2. Natural cider electrophoregram. The molecular masses of the proteins can be seen in Table 3 .

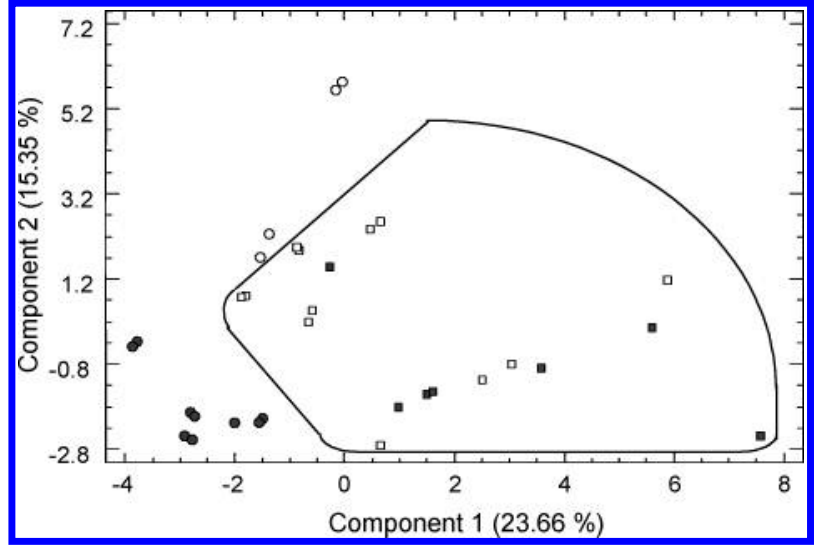

Figure 3. Plot of the ciders on the plane formed by the two first predictive principal components (legend as in Figure 1).

Table 4. Loadings of 33 Polypeptides $(\mathrm{P})$ Corresponding to the Two First Principal Components (PC) ${ }^{a}$

\begin{tabular}{lrrrrr}
\hline $\begin{array}{c}\text { polypeptide } \\
\text { (kDa) }\end{array}$ & \multicolumn{1}{c}{ PC1 } & \multicolumn{1}{c}{ PC2 } & $\begin{array}{c}\text { polypeptide } \\
(\mathrm{kDa})\end{array}$ & \multicolumn{1}{c}{ PC1 } & \multicolumn{1}{c}{ PC2 } \\
\hline P1 (8.0) & -0.033 & -0.046 & P18 (52.0) & 0.193 & 0.151 \\
P2 (12.1) & 0.071 & 0.186 & P19 (57.2) & 0.197 & 0.022 \\
P3 (13.1) & -0.076 & 0.097 & P20 (60.6) & -0.091 & 0.170 \\
P4 (14.4) & 0.152 & 0.093 & P21 (67.3) & 0.302 & 0.137 \\
P5 (15.7) & 0.180 & 0.168 & P22 (72.6) & 0.163 & -0.214 \\
P6 (18.0) & 0.168 & 0.250 & P23 (75.3) & 0.333 & -0.069 \\
P7 (20.0) & -0.073 & 0.218 & P24 (78.6) & 0.134 & 0.216 \\
P8 (21.0) & 0.035 & 0.291 & P25 (86.0) & 0.087 & 0.047 \\
P9 (22.9) & 0.044 & 0.344 & P26 (93.5) & 0.312 & -0.032 \\
P10 (24.8) & -0.151 & 0.228 & P27 (95.5) & 0.182 & 0.135 \\
P11 (25.8) & -0.038 & 0.392 & P28 (101.2) & 0.036 & 0.193 \\
P12 (26.8) & 0.192 & -0.079 & P29 (111.4) & 0.161 & -0.101 \\
P13 (28.9) & 0.284 & -0.110 & P30 (122.0) & 0.207 & 0.047 \\
P14 (30.6) & 0.082 & -0.174 & P31 (134.4) & 0.223 & 0.027 \\
P15 (35.5) & 0.201 & -0.115 & P32 (140.9) & 0.254 & 0.012 \\
P16 (39.7) & 0.071 & 0.231 & P33 (154.4) & 0.160 & -0.116 \\
P17 (45.0) & 0.152 & -0.173 & & & \\
& & & & &
\end{tabular}

\footnotetext{
${ }^{a}$ The most significant values are given in boldface type.
}

of their interactions. Table $\mathbf{5}$ shows the significant coefficients; in most cases they are positive, which means that these proteins help to attain high values of the foam parameters. The
Table 5. Pearson Coefficients between Foam Parameters and Polypeptides, with Significance Levels of $p<0.05$

\begin{tabular}{|c|c|c|c|c|c|}
\hline & ST & & FS & & $\mathrm{FH}$ \\
\hline P4 (14.4 kDa) & 0.537 & P6 (18.0 kDa) & 0.589 & P6 (18.0 kDa) & 0.428 \\
\hline P6 (18.0 kDa) & 0.514 & P13 (28.9 kDa) & 0.413 & P13 (28.9 kDa) & 0.412 \\
\hline P13 (28.9 kDa) & 0.601 & P15 (35.5 kDa) & 0.379 & P15 (35.5 kDa) & 0.521 \\
\hline P15 (35.5 kDa) & 0.551 & P16 (39.7 kDa) & 0.427 & P25 (86.0 kDa) & 0.415 \\
\hline P18 (52.0 kDa) & 0.368 & P18 (52.0 kDa) & 0.505 & P26 (93.5 kDa) & 0.432 \\
\hline P19 (57.2 kDa) & 0.717 & P21 (67.3 kDa) & 0.522 & P28 (101.2kDa) & -0.378 \\
\hline P21 (67.3 kDa) & 0.553 & P23 (75.3 kDa) & 0.359 & P29 (111.4kDa) & 0.747 \\
\hline P22 (72.6 kDa) & 0.434 & P24 (78.6 kDa) & 0.492 & & \\
\hline P23 (75.3 kDa) & 0.718 & P26 (93.5 kDa) & 0.464 & & \\
\hline P25 (86.0 kDa) & 0.528 & P28 (101.2kDa) & -0.373 & & \\
\hline P26 (93.5 kDa) & 0.763 & P29 (111.4kDa) & 0.613 & & \\
\hline P29 (111.4kDa) & 0.670 & & & & \\
\hline P30 (122.0kDa) & 0.710 & & & & \\
\hline P32 (140.9kDa) & 0.371 & & & & \\
\hline
\end{tabular}

stabilization time (ST) is the parameter with more and higher significant Pearson coefficients. Most of these cases belong to proteins with a high molecular weight, so this kind of protein seems to be a foam stabilizer.

To complete these initial conclusions, we carried out a more complete CCA and PLSR.

$C C A$. The purpose of CCA is to summarize or explain the relationships between two sets of variables by finding the linear combinations of these variables that have the highest correlation.

The variables were separated in two sets: the first one was formed by the foam parameters and the second one by the polypeptides. At the same time, we divided the polypeptides into three groups by means of their molecular mass (low, 8.0$25.8 \mathrm{kDa}$; medium, $26.8-72.6 \mathrm{kDa}$; and high, 75.3-154.4 kDa). Each group was correlated with the first set of foam parameters, thus obtaining the estimated correlations between them, which are illustrated in Table 6. In this case, three sets of linear combinations were obtained in each group of proteins. However, not all of them are statistically significant at the $95 \%$ confidence level. In the group of low molecular weight proteins, the members of the third set have $p$ values of $>0.05$. In this group of proteins, the canonical coefficients are lower than the coefficients of the other groups. In fact, if we select the higher correlation coefficient of each group of proteins, we observe that the higher the molecular weight, the higher the correlation, 
Table 6. Canonical Correlations between the Three Groups of Proteins and the Foam Parameters for Three Linear Combinations ${ }^{a}$

\begin{tabular}{lcccc}
\hline \multicolumn{1}{c}{ group } & no. & eigenvalues & $\begin{array}{c}\text { canonical } \\
\text { correlation }\end{array}$ & p value \\
\hline low mol mass & 1 & 0.8752 & 0.9355 & 0.0000 \\
& 2 & 0.7724 & 0.8789 & 0.0008 \\
& 3 & 0.3825 & 0.6184 & 0.2539 \\
medium mol mass & 1 & 0.9132 & 0.9556 & 0.0000 \\
& 2 & 0.8110 & 0.9005 & 0.0000 \\
high mol mass & 3 & 0.7146 & 0.8453 & 0.0005 \\
& 1 & 0.9473 & 0.9733 & 0.0000 \\
& 2 & 0.7081 & 0.8415 & 0.0001 \\
& 3 & 0.6609 & 0.8130 & 0.0025
\end{tabular}

a Significant correlations $(p<0.05)$ are given in boldface type.

Table 7. PLS Parameters of the Multiple Regression Analysis

\begin{tabular}{ccccc}
\hline $\begin{array}{c}\text { foam } \\
\text { parameter }^{\text {a }}\end{array}$ & $\begin{array}{c}\text { no. of } \\
\text { latent } \\
\text { variables }\end{array}$ & $\begin{array}{c}\text { cross-validated } \\
\text { explained } \\
\text { variance (\%) }\end{array}$ & $\begin{array}{c}\text { explained } \\
\text { variance } \\
(\%)\end{array}$ & $\begin{array}{c}\text { multiple linear } \\
\text { correlation } \\
\text { coefficient (\%) }\end{array}$ \\
\hline FH & 1 & 30.8 & 35.5 & 37.6 \\
FS & 3 & 46.6 & 86.2 & 87.3 \\
ST & 3 & 82.2 & 87.8 & 89.0
\end{tabular}

${ }^{a}$ Maximum height (FH), stability height (FS), and stability time (ST).

which means that high molecular weight proteins have the main influence on foam formation and stabilization in cider.

$P L S R$. This analysis was used to evaluate correlations between foam parameters [criterion or response variables $(r=3), \mathrm{FH}$, FS, and ST] and polypeptides ( $p=33$, predictor variables), with predictive purpose. The database consisted of a 32 (ciders) $\times 36$ (predictor and criterion variables) matrix. Significant latent variables (principal components) were computed by maximizing cross-validated explained variance $\left(\mathrm{CVEV}_{\mathrm{r}}\right)$ for each foam parameter $(r)$, using three groups of cancellation. At the same time, predictor variables $(p)$ were chosen according to their weighted importance parameter $\left(I_{\mathrm{p}}\right)$. The cutoff value chosen for $I_{\mathrm{p}}$ was 0.02 . In accordance with this criterion, 21 predictor variables were selected. Table 7 shows the evaluated PLS parameters. As can be seen, the foam parameters with the highest correlation were FS and ST, which is in agreement with the Pearson coefficients (Table 5), computing multiple linear correlation coefficients of $>87 \%$. The most relevant predictor variable was the polypeptide with a molecular mass of 111.4 $\mathrm{kDa}$. As described by Bamforth (17), foam stability is related to surface elasticity, surface tension, and surface viscosity, the proteins with high molecular mass probably being the most appropriate for stabilizing the film of bubbles.

As an example, Figure 4 shows the mathematical equation that predicts stability time using a PLS model with three latent variables and 21 predictor variables (polypeptides) after the removal of an outlier, giving an $r^{2}$ of 0.80 . The outlier corresponds to a cider with serious sensory defects, because it presented persistent foam. Two groups of ciders may be detected on the graph, being differentiated by the press technology used.

We may therefore conclude that the PLSR technique allowed a feasible mathematical model for predicting stabilization time of foam in cider to be computed, the most relevant predictor variable being a polypeptide of high molecular size. This could confirm that proteinaceous materials with a high surface viscosity, a low diffusion coefficient, and a large size promote higher stability in foam.

In conclusion, we may state that ciders with different foam assessments and made by means of different technologies show

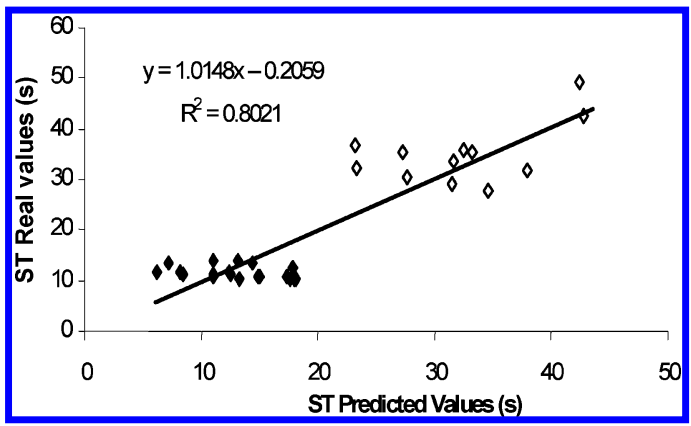

Figure 4. Predicted ST values $(n=32)$ using the PLS model with 3 latent variables and 21 polypeptides: $(\diamond)$ ciders made via a fast extraction process; $(\checkmark)$ ciders made via a slow extraction process.

differences in their protein profiles, based on molecular weight, which allows their characterization. This reveals the importance of determining the characteristics of the polypeptides, such as their molecular weight, because the total protein content was not able to clearly differentiate the categories of ciders.

It is also important to point out that cider foamability can be influenced by the juice extraction technology used and that this visual aspect is clearly affected by the polypeptide composition of the cider. Thus, the molecular weight of the proteins is strongly related to foam parameters, the high molecular weight proteins being the most influential and the stabilization time being the most affected parameter.

\section{ACKNOWLEDGMENT}

We thank the SERIDA Food Technology research group for their assistance and supply of experimental ciders.

\section{LITERATURE CITED}

(1) Mangas Alonso, J. J.; Moreno, J.; Rodríguez, R.; Picinelli, A.; Suárez, B. Analysis of polysaccharides in cider. Their effect on sensory foaming properties. J. Agric. Food Chem. 1999, 47, $152-156$.

(2) Margolles Cabrales, I.; Arias Abrodo, P.; Blanco-Gomis, D. Fatty acid composition of cider obtained either by traditional or controlled fermentation. J. Agric. Food Chem. 2003, 51, 63146316.

(3) Siebert, K.; Knudson, E. J. The relationship of beer high molecular weight protein and foam. Tech. O.-Master Brew. Assoc. Am. 1989, 26, 139-146.

(4) Kano, Y.; Kaminura, M. Simple methods for determination of the molecular weight distribution of beer proteins and their application to foam and haze studies. J. Am. Soc. Brew. Chem. 1993, 51, 21-28.

(5) Hsu, J. C.; Heatherbell, D. A.; Flores, J. H.; Watson, B. T. Heatunstable proteins in grape juice and wine. II. Characterization and removal by ultrafiltration. Am. J. Enol. Vitic. 1987, 38, 1722

(6) Polo, M. C.; Cáceres, I.; Palop, L. I.; Dizy, M.; Pueyo, E.; MartínÁlvarez, P. J. Proceedings of the 6th International Flavor Conference, Greece 1989, July, 5-7.

(7) Zayas, J. F. Foaming properties of proteins. In Functionality of Proteins in Food; Springer-Verlag: Berlin, Germany, 1997; 261 pp.

(8) Ferreira, I. M. P. L. V. O.; Jorge, K.; Nogueira, L. C.; Silva, F.; Trugo, L. C. Beer foam stability: influence of hydrophobic polypeptides, iso-alpha-acids composition and malto-oligosaccharides. J. Agric. Food Chem. 2005, 53, 5976-4981.

(9) Brissonnet, F.; Maujean, A. Identification of some foam-active compounds in Champagne base wines. Am. J. Enol. Vitic. 1991, 42 (2), 97-102. 
(10) Andrés-Lacueva, C.; Lamuela-Raventós, R. M.; Buxaderas, S.; Torre-Boronat, M. C. Influence of variety and aging on foaming properties of cava (sparkling wine). 2. J. Agric. Food Chem. 1997, 45, 2520-2525.

(11) Andrés-Lacueva, C.; López-Tamames, E.; Lamuela-Raventós, R. M.; Buxaderas, S.; Torre-Boronat, M. C. Characteristics of sparkling base wines affecting foam behavior. J. Agric. Food Chem. 1996, 44, 989-995.

(12) Blanco, D.; Junco, S.; Expósito, Y.; Gutiérrez, M. D. Size-based separations of proteins by capillary electrophoresis using linear polyacrylamide as a sieving medium: model studies and analysis of cider proteins. Electrophoresis 2003, 24, 1391-1396.

(13) Blanco, D.; Junco, S.; Expósito, Y.; Gutiérrez, M. D. Study of various treatments to isolate low levels of cider proteins to be analyzed by capillary sieving electrophoresis. J. Liq. Chromatogr. Relat. Technol. 2004, 27, 1523-1539.
(14) Bradford, M. M. A rapid and sensitive for the quantitation of microgram quantities of protein utilizing the principle of proteindye binding. Anal. Biochem. 1976, 72, 248-254.

(15) Forina, M.; Leardi, R.; Armanino, C.; Lanteri, S. An extendable package of programs for data exploration, classification, and correlation; Elsevier: Amsterdam, 1988.

(16) Bamforth, C.W. The relative significance of physics and chemistry for beer foam excellence: theory and practice. J. Inst. Brew. 2004, 110 (4), 259-266.

(17) Bamforth, C.W. The foaming properties of beer. J. Inst. Brew. 1985, 91 (Nov-Dec), 370-383.

Received for review October 8, 2006. Revised manuscript received January 14, 2007. Accepted January 17, 2007. We thank the University of Oviedo for financial support in the form of a Ph.D. grant.

JF062891L 